УДК 624.131.37:624.131.43

ОПРЕДЕЛЕНИЕ ФИЗИЧЕСКИХ ХАРАКТЕРИСТИК ОДНОРОДНЫХ ГРУНТОВ С НИЗКОЙ СТРУКТУРНОЙ ПРОЧНОСТЬЮ

\author{
Кузьмин Г.П., Вахрин И.С., Лобанов А.Л.
}

ФГБУН Институт мерзлотоведения им. П.И. Мельникова СО РАН, Якутск, e-mail:kuzmin@mpi.ysn.ru,VakhLIG2010@yandex.ru,art2356-1991@yandex.ru

\begin{abstract}
При проведении инженерно-геологических изысканий на строительной площадке предусматривается определение основных физических характеристик грунтов. Для этого из зоны возможного влияния фундаментов сооружений на напряженно-деформированное состояние основания отбирают образцы с сохранением состава и строения грунтов. В настоящее время основным способом выемки образцов из массива является бурение с выдачей керна ненарушенного сложения. При таком способе отбора проб из отложений грунтов с низкой структурной прочностью образцы разрушаются. Такие образцы пригодны для определения только плотности твердых частиц и влажности грунта, так как в формулах для их расчёта не содержится объём образца. Для однородных по составу и строению отложений грунтов с низкой структурной прочностью предлагается новый способ определения физических характеристик грунтов, основанный на закономерностях компрессионного сжатия образцов, отобранных на поверхности массива, и распределения влажности грунта по глубине внутри массива. Изложена методика отбора образцов с поверхности массива с сохранением строения грунта. Приведены расчётные зависимости плотности твёрдых частиц, начальных значений и при давлениях компрессионного сжатия плотности сухого грунта и пористости. Показано определение плотности грунта в массиве, которая зависит от плотности сухого грунта, влажности и давления на расчётной глубине от действия вышележащей толщи. Изложено определение из условия равенства давлений в компрессионном приборе и массиве глубины, на которой формируются найденные значения физических характеристик грунта. Приведены результаты определения физических характеристик талых намывных грунтов в пойме р. Лены в г. Якутске.
\end{abstract}

Ключевые слова: образец, физические характеристики, деформации, компрессионное сжатие, давление, массив, плотность, влажность, пористость, глубина

\title{
DETERMINING THE PHYSICAL PARAMETERS OF HOMOGENEOUS NON-COHESIVE SOILS
}

\author{
Kuzmin G.P., Vakhrin I.S., Lobanov A.L. \\ Melnikov Permafrost Institute SB RAS, Yakutsk,e-mail: kuzmin@mpi.ysn.ru, \\ VakhLIG2010@yandex.ru,art2356-1991@yandex.ru
}

\begin{abstract}
Geotechnical site investigation programs involve determination of the main physical properties of soils and rocks. For this purpose, undisturbed samples are taken from the zone of influence of a foundation without altering the soil composition or structure. At present, drilling with undisturbed core retrieval is the primary technique used to obtain samples from the ground. However, samples taken from non-cohesive sediments with this technique are easily destroyed and can only be used for the determination of solids density and soil moisture content because the respective constitutive equations require no sample volume. We propose a new method for determining the physical parameters applicable to non-cohesive soils of homogeneous composition and structure. The method is based on consolidation behavior of samples obtained from the ground surface and on water content distribution with depth. In this paper, a sampling procedure is described to retrieve undisturbed soil samples from the ground mass surface. Equations relating solids density, dry density and porosity at initial and consolidation pressures are given. Determination of in-situ soil density is demonstrated, which depends on dry density, moisture content and overburden pressure. From the condition of equal pressures in the consolidometer and ground mass, it is shown how to find a depth at which the derived values of soil physical parameters are formed. Physical characteristics are presented which were obtained for unfrozen fill soils in the Lena River floodplain at Yakutsk.
\end{abstract}

Keywords: sample, physical properties, deformations, consolidation, pressure, ground mass, density, water content, porosity, depth

При проектировании зданий и сооружений необходимы данные о физических характеристиках грунтов основания, которые определяют в процессе выполнения инженерно-геологических изысканий на строительной площадке [1]. Физические свойства грунтов изучают по образцам (пробам), отбираемым из массива с сохранением естественного состава и строения их [2]. Отбор образцов в настоящее время осуществляют в основном из буровых кер- нов. Однако такой способ отбора образцов грунта с низкой структурной прочностью не пригоден. Образцы в процессе бурения скважины и выемки керна из буровых труб разрушаются и могут быть использованы для определения только влажности и плотности твёрдых частиц грунта, расчётные зависимости которых не содержат объёма образца. При бурении теряют связность большая часть талых грунтов, талые и мёрзлые пески в дюнных отложе- 
ниях и намывных толщах. В криолитозоне грунты с низкой структурной прочностью имеют место и в природных условиях, и на искусственно созданных строительных площадках. Дюнные песчаные отложения (тукуланы) широко распространены в междуречье р. Лены и её притока р. Вилюй. Мощные отложения под действием ветра перемещаются, частично или полностью засыпая деревья песком. В г. Якутске на пойме р. Лены гидравлическим способом созданы две намывные территории для строительства жилых домов мощностью в понижениях до 15 м. Из таких отложений отбор образцов ненарушенного сложения распространенным в криолитозоне буровым способом невозможен. Поэтому ограничиваются получением тех характеристик грунта, для определения которых нет необходимости сохранять целостность образца. В связи с этим поставлена цель разработать способ определения в массиве физических характеристик однородных грунтов с низкой структурной прочностью.

Физические характеристики однородных талых и сыпучемёрзлых грунтов предлагается определять новым способом, основанным на закономерностях деформации образцов при компрессионном сжатии, отбираемых на поверхности массива с сохранением сложения, и зависимости влажности грунта в массиве в пределах изучаемого слоя. Отбор образцов с поверхности массива позволяет определить их объём и тем самым найти плотность сухого грунта и его пористость, которые являются начальными значениями характеристик образца, испытываемого на компрессионное сжатие. Давление в компрессионном приборе, плотность сухого грунта и пористость при этом давлении соответствуют значениям их в массиве на определенной глубине. Влажность грунта в массиве определяется по образцам нарушенного сложения, отбираемым из буровых кернов.

Плотность сухого грунта в зависимости от деформации образца при компрессионном сжатии и влажность грунта по глубине позволяют найти выражения плотности грунта и давления в массиве. Затем из условия равенства давлений в компрессионном приборе и массиве рассчитывается глубина, на которой формируются найденные значения физических характеристик грунта. При одинаковых давлениях в компрессионном приборе и массиве плотность сухого грунта и пористость образца в приборе и грунта в массиве равны. Эти физи- ческие характеристики грунта на ступенях давления компрессионного сжатия определяются по деформациям образца [3]. Плотность грунта в массиве, от которой зависит давление, в однородных грунтах определяется по значениям плотности сухого грунта и влажности.

\section{Материалы и методы исследования}

Образцы однородного грунта для определения начальных значений физических характеристик и испытания на компрессионное сжатие отбирают на поверхности массива с сохранением их сложения. Показатели физических свойств грунта определяют по известным зависимостям [4]: плотность твердых частиц

$$
\rho_{s}=\frac{m_{d}}{V_{d}}
$$

начальная плотность сухого грунта

$$
\rho_{d 0}=\frac{m_{d}}{V_{0}},
$$

начальная пористость грунта

$$
n_{0}=\frac{\rho_{s}-\rho_{d 0}}{\rho_{s}},
$$

где $m_{d}$ - масса сухого образца; $V_{d}$ - объем твердых частиц образца; $V_{0}-$ начальный объём образца.

В процессе компрессионного сжатия образца объём его уменьшается и в условиях невозможности бокового расширения выражается зависимостью

$$
V_{i}=S\left(h-\Delta h_{i}\right)
$$

где $S$ - площадь поперечного сечения образца; $h$ - начальная высота образца; $\Delta h_{i}-$ продольная деформация образца на $i$-й ступени давления.

На ступенях давления компрессионного сжатия образца грунта на основании (4) найдены выражения [5]:

плотности сухого грунта

$$
\rho_{d i}=\frac{\rho_{d 0}}{\left(1-\frac{\Delta h_{i}}{h}\right)},
$$

и пористости

$$
n_{i}=1-\frac{\rho_{d 0}}{\rho_{s}\left(1-\frac{\Delta h_{i}}{h}\right)} .
$$


Плотность грунта в массиве, от которой зависит давление, с учетом (5) выражается зависимостью

$$
\rho_{i}=\rho_{d i}(1+w)=\frac{\rho_{d o}}{\left(1-\frac{\Delta h_{i}}{h}\right)}(1+w),
$$

где $w$ - влажность грунта.

Влажность грунта в исследуемом слое определяется по образцам, извлекаемым из массива буровым способом, и должна быть выражена зависимостью от глубины. Табличное представление влажности грунта по глубине не даёт возможности найти глубины, на которых значения плотности сухого грунта и пористости в компрессионном приборе и массиве равны. В грунтах с высокой фильтрующей способностью в условиях свободного оттока воды влажность грунта небольшая и вследствие этого она существенного влияния на величину плотности грунта и давление в массиве не оказывает. Для оценки изменения физических характеристик однородных грунтов в массиве предлагаемым методом рассмотрим случай постоянной влажности по глубине, как в намывных песчаных грунтах в пойме р. Лены в г. Якутске.

При постоянной влажности грунта по глубине давление в основании $i$-го слоя можно представить в виде

$$
p_{i}=p_{i-1}+\frac{\rho_{i-1}+\rho_{i}}{2}(1+w)\left(z_{i}-z_{i-1}\right),
$$

где $z$ - глубина.

Из (8) находим глубину в массиве, на которой формируются плотность сухого грунта и пористость, равные по величине плотности сухого грунта и пористости в компрессионном приборе на $i$-й ступени давления:

$$
z_{i}=z_{i-1}+\frac{2\left(p_{i}-p_{i-1}\right)}{\left(\rho_{i}+\rho_{i-1}\right)(1+w)} .
$$

Таким образом, способ определения физических характеристик однородных грунтов со слабой структурной прочностью включает следующее:

- отбор образцов с поверхности массива, определение плотности твердых частиц, начальных значений плотности сухого грунта и пористости по формулам (1), (2) и (3) соответственно;

- компрессионные испытания образца и определение на ступенях давления плот- ности сухого грунта и пористости по формулам (5) и (6);

- бурение скважины, отбор образцов из кернов, определение их влажности и установление зависимости влажности от глубины в пределах исследуемого слоя;

- определение плотности грунта по формуле (7) в пределах исследуемого слоя;

- определение по формуле (9) глубины в массиве, на которой формируются найденные значения физических характеристик грунта.

Как видно из изложенного все физические характеристики однородных грунтов в массиве определяются по данным инженерно-геологических изысканий, выполняемых на строительных площадках. Способ может применяться как в области распространения многолетнемерзлых грунтов, так и в области сезонного промерзания грунтов.

\section{Результаты исследования и их обсуждение}

В пойме р. Лены в г. Якутске возведены строительные площадки способом намыва руслового песка - кварталы 202 и 203. Первая из них полностью застроена жилыми домами, вторая освоена не полностью (рис. 1).

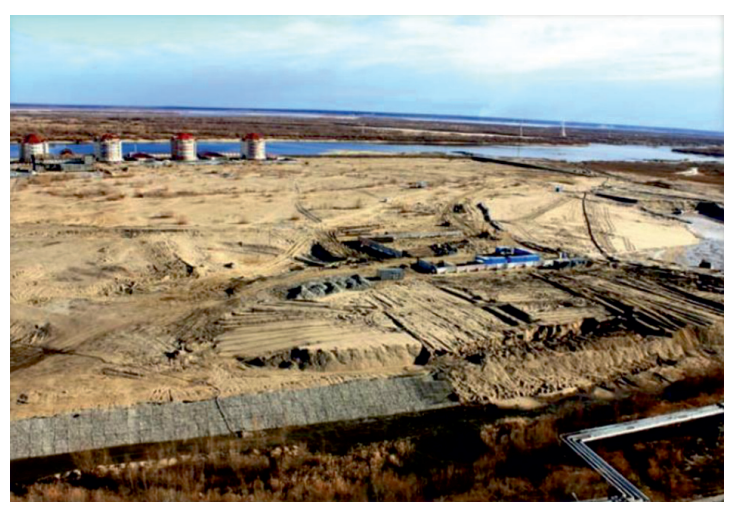

Рис. 1. Начальный вид намывной территории квартала 203 в г. Якутске

Влажность намывных грунтов на разных участках 203 квартала и по глубине по данным инженерно-геологических изысканий одинакова и составляет 0,05 д.е. (табл. 1).

Результаты определения предложенным способом давления и физических характеристик намывных грунтов в 203 квартале г. Якутска, которые согласно [6] относятся к пескам, представлены в табл. 2 и на рис. $2,3$. 
Таблица 1

Влажность намывных грунтов на территории квартала 203 г. Якутска

\begin{tabular}{|c|l|c|c|c|}
\hline \multirow{2}{*}{$\begin{array}{c}\text { № } \\
\text { п/п }\end{array}$} & \multicolumn{1}{|c|}{ Наименование } & \multicolumn{3}{|c|}{ Номера домов } \\
\cline { 3 - 5 } & & $2-1$ & $2-5$ & $3-4$ \\
\hline 1 & Количество скважин, шт. & 15 & 7 & 3 \\
\hline 2 & Мощность слоя, м & 7,4 & 5,7 & 6,7 \\
\hline 3 & Средняя влажность, д.е. & 0,05 & 0,05 & 0,04 \\
\hline
\end{tabular}

Таблица 2

Физические характеристики намывных грунтов на территории квартала 203 г. Якутска

\begin{tabular}{|c|c|c|c|c|c|c|c|}
\hline $\begin{array}{c}\text { № } \\
\Pi / \Pi\end{array}$ & $p$, МПа & $\Delta h, \mathrm{MM}$ & $\Delta h / h$ & $\rho, \mathrm{\kappa} / \mathrm{M}^{3}$ & $\rho_{d}, \mathrm{\kappa} \Gamma / \mathrm{M}^{3}$ & $n, \%$ & $z, \mathrm{M}$ \\
\hline 1 & 0 & 0 & 0 & 1464 & 1394 & 47,4 & 0 \\
\hline 2 & 0,1 & 0,12 & 0,0048 & 1471 & 1401 & 47,34 & 6,49 \\
\hline 3 & 0,15 & 0,16 & 0,0064 & 1473 & 1403 & 47,26 & 9,73 \\
\hline 4 & 0,2 & 0,19 & 0,0076 & 1475 & 1405 & 47,19 & 12,96 \\
\hline 5 & 0,25 & 0,22 & 0,0088 & 1477 & 1407 & 47,13 & 16,18 \\
\hline
\end{tabular}

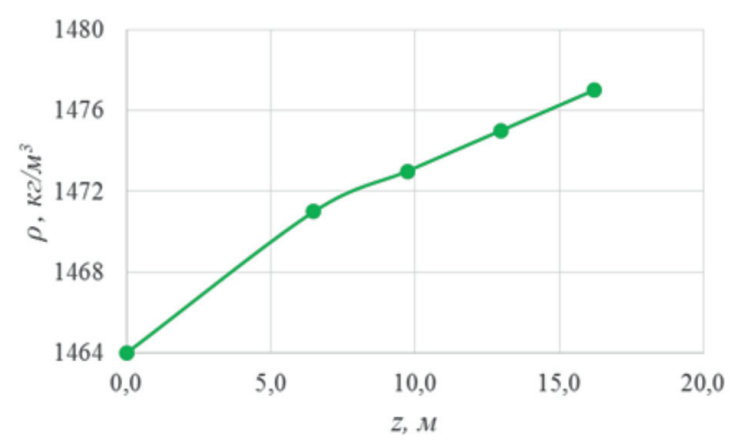

a)

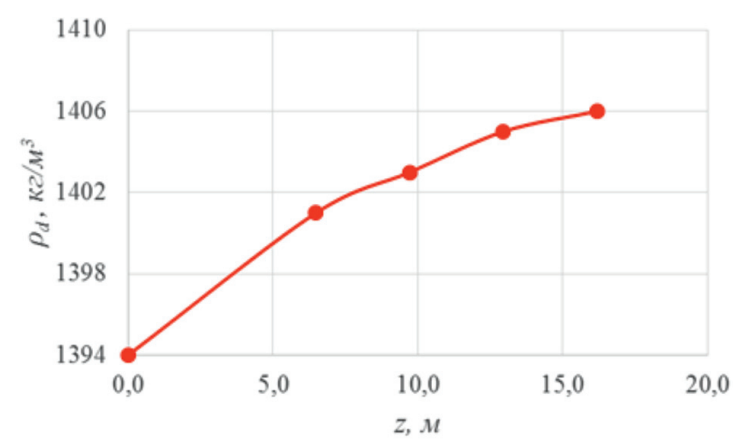

б)

Рис. 2. Графики изменения по глубине $\rho$ (a)

и $\rho_{d}(б)$ намывных песчаных грунтов в квартале 203 г. Якутска

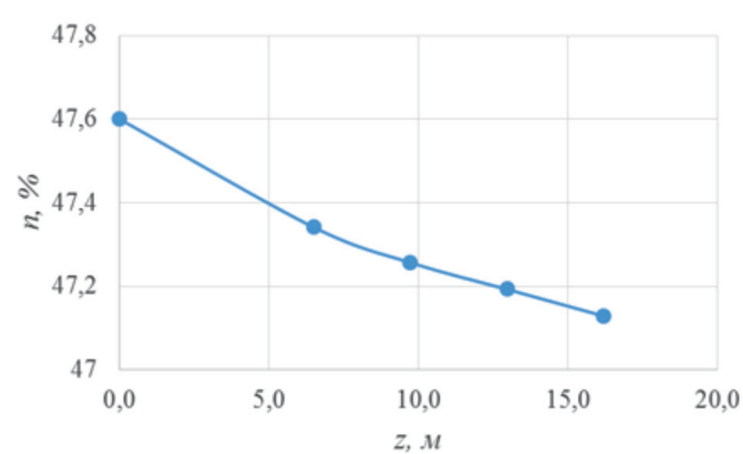

a)

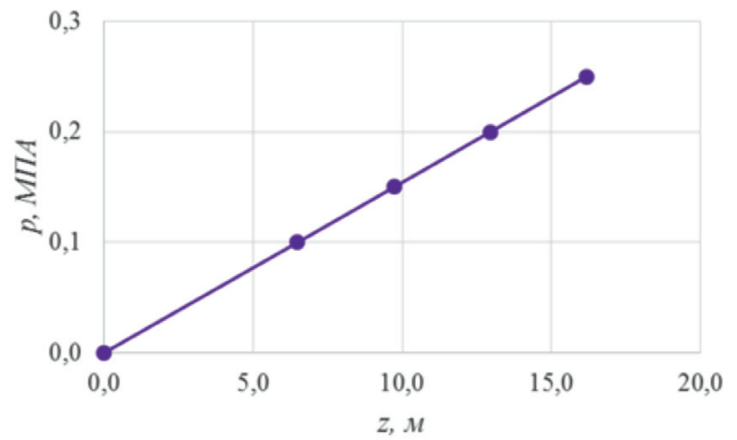

б)

Рис. 3. Графики изменения по глубине п (a) и р (б) намывныхх песчаных грунтов в квартале 203 г. Якутска 
Как видно из рис. 2, физические характеристики намывных песчаных грунтов изменяются по глубине незначительно, причем с затухающей скоростью. Небольшое уменьшение пористости грунта по глубине обусловлено малой сжимаемостью грунта под нагрузкой и небольшим ростом давления вследствие незначительного повышения плотности грунта, изменение которой, в свою очередь, зависит от мало изменяющейся плотности сухого грунта и его низкой влажности.

\section{Заключение}

Разработан новый способ определения физических характеристик однородных грунтов с низкой структурной прочностью, основанный на данных определения физических характеристик и закономерностях компрессионного сжатия образцов, отбираемых на поверхности массива с сохранением их сложения, а также функции влажности грунта по глубине. Параметры для расчёта физических характеристик грунта можно получить в процессе выполнения инженерно-геологических изысканий. Физические характеристики намывных песча- ных грунтов небольшой влажности изменяются по глубине незначительно.

\section{Список литературы / References}

1. Хрусталёв Л.Н. Основы геотехники в криолитозоне: учебник. М.: ИНФРА-М, 2019. 543 с.

Khrustalev L.N. Fundamentals of Geotechnics in Permafrost: textbook. M.: INFRA-M, 2019. 543 p. (in Russian).

2. ГОСТ 5180-2015. Грунты. Методы лабораторного определения физических характеристик. М.: Стандартинформ, 2016. 23 с

3. Вахрин И.С., Кузьмин Г.П. Деформационные характеристики искусственно приготовленных образцов мерзлых грунтов при оттаивании // Успехи современного естествознания. 2020. № 7. С. 70-76. DOI: 10.17513/use.37434.

Vakhrin I.S., Kuzmin G.P. Thaw deformation characteristics of artificially prepared frozen soil samples // Advances in current natural sciences. 2020. № 7. P. 70-76 (in Russian).

4. Трофимов В.Т., Вознесенский Е.А., Королёв В.А. Инженерная геология России. Том 1. Грунты России. М.: КДУ, 2011. 672 с

Trofimov V.T., Voznesenskiy E.A., Korolev V.A. Engineering Geology of Russia. Vol. 1. Soils of Russia. M.: KDU, 2011. 672 p. (in Russian).

5. Болдырев Г.Г. Методы определения механических свойств грунтов с комментариями к ГОСТ 12248-2010: монография. 2-е изд., доп. и испр. М.: ООО «Прондо», 2014. $812 \mathrm{c}$

Boldyrev G.G. Methods for Determining the Mechanical Properties of Soils with Comments to GOST 12248-2010. 2nd ed., updated. M.: OOO «Prondo», 2014. 812 p. (in Russian).

6. ГОСТ 25100-2011. Грунты. Классификация. М.: Межгосударственный стандарт, 2013. 63 с. 